\title{
ANÁLISE DA EVOLUÇÃO DO ÍNDICE MUNICIPAL INDUSTRIAL DE SANTA CATARINA ENTRE OS ANOS DE 2002 E 2016
}

\author{
Thiago Pegoretti Moser ${ }^{1}$ \\ Marcia Regina Gabardo da Camara² \\ Carlos Eduardo Caldarelli ${ }^{3}$
}

Resumo: O objetivo do estudo é examinar a evolução da distribuição do setor industrial nos municípios catarinenses e suas transformações nos anos de 2002, 2009 e 2016. Utilizaram-se duas metodologias: análise de componentes principais para a construção de um Índice Municipal Industrial (IMI) e, a partir deste, a ferramenta de análise exploratória de dados espaciais. A estatística Local de Moran permitiu identificar clusters cujos resultados apontam regiões de concentração industrial, as quais estão autocorrelacionadas. Verificou-se aumento do IMI médio, mas as regiões mais industrializadas registraram redução, como Joinville, Jaraguá do Sul, Blumenau e Brusque.

Palavras-chave: Autocorrelação espacial. Indústria Catarinense. Cluster.

\section{EVOLUTION'S ANALYSIS OF THE INDUSTRIAL MUNICIPAL INDEX OF SANTA CATARINA STATE BETWEEN THE YEARS OF 2002 AND 2016}

Abstract: The aim of this research is to examine the distribution's evolution of the industrial sector in the municipalities of Santa Catarina State and its transformations for the years 2002, 2009 and 2016. We used two methodologies to measure the evolution: Principal Component Analysis to build an Industrial Municipal Index (IMI) of Santa Catarina cities, which is used with Spatial Data Analysis. The Moran's I statistics appoint to regions of industrial concentration witch areas are spatially autocorrelated. The results revealed an increase in the IMI average, although in the most industrialized regions there was a reduction, such as in Joinville, Jaraguá do Sul, Blumenau and Brusque.

Keywords: Spatial Autocorrelation. Industry of Santa Catarina State. Cluster.

\section{ANÁLISIS DE LA EVOLUCIÓN DEL ÍNDICE MUNICIPAL INDUSTRIAL DE SANTA CATARINA ENTRE LOS AÑOS DE 2002 Y 2016}

Resumen: El objetivo de este trabajo es examinar la evolución de la distribución del sector industrial en los municipios de Santa Catarina y sus transformaciones para los años 2002, 2009 y 2016. Para esto, se utilizan dos metodologías: análisis de los componentes principales para la construcción de un Índice Municipal Industrial (IMI) y a partir de ahí la herramienta de análisis exploratoria de datos espaciales. La estadística local de Moran apuntan a regiones de concentración industrial, que están autocorrelacionadas. Además, hubo un aumento en el IMI promedio, aunque en las

\footnotetext{
${ }^{1}$ Central de Água, Esgoto e Serviços Concedidos do Litoral do Paraná, Paranaguá, Brasil, tpmoser@hotmail.com, https://orcid.org/0000-0002-2713-1081

2 Universidade Estadual de Londrina, Departamento de Economia, Londrina, Brasil, mgabardo@uel.br, https://orcid.org/0000-0002-3710-1783

3 Universidade Estadual de Londrina, Departamento de Economia, Londrina, Brasil, caldarelli@uel.br, https://orcid.org/0000-0002-6739-7183
} 
regiones más industrializadas hubo una reducción, como em Joinville, Jaraguá do Sul, Blumenau y Brusque.

Palabras clave: Autocorrelación espacial. Industria catarinense. Cluster.

\section{Introdução}

Há muitos autores que imputam ao setor secundário da economia uma relevância maior em comparação ao básico e de serviços. A importância da indústria se dá num contexto inovador e de vanguarda que suas externalidades positivas produzem. A indústria é um dos principais mecanismos para a difusão do processo tecnológico, crescimento a longo prazo, geração de empregos e aumento da renda per capita (LANGONI, 1976; OREIRO; FEIJO, 2010).

Segundo o IBGE (2019), em 2002 a indústria de Santa Catarina contribuía com $31 \%$ do valor adicionado do Estado e $35 \%$ dos empregos. No fim do período analisado, em 2016, o valor agregado industrial reduziu 4 pontos percentuais enquanto a participação dos empregos 5 pontos.

Historicamente o Estado de Santa Catarina atinge desempenhos superiores à média brasileira. Destaca-se em aspectos tecnológicos, produtivos, comércio exterior e na geração de empregos cuja evolução culminou em 2015 na unidade da federação com a maior proporção $(75,6 \%)$ de pessoas com 16 anos ou mais ocupadas em empregos formais (FIESC; 2017).

Desta forma, este estudo propôs a seguinte questão de pesquisa: qual a evolução da estrutura espacial e do desempenho da indústria do Estado de Santa Catarina no período entre 2002 e $2016 ?$

O objetivo geral da pesquisa foi examinar a evolução da distribuição do setor industrial em Santa Catarina e suas transformações recentes. Logo, buscou-se identificar a existência de algum tipo de padrão na distribuição industrial espacial no Estado e em caso positivo, se houve modifiicações ao longo do tempo. De forma específica, examinou-se se existe autocorrelação espacial entre as cidades, ou seja, se uma cidade altamente industrializada possui uma cidade vizinha com essa mesma característica.

Para alcançar esses objetivos, utiliza-se análise de componentes principais (PCA) capaz de refletir a estrutura produtiva de um município. O índice foi construído a partir da combinação de dados de emprego, de valor adicionado e de exportações. Foi criada uma medida para cada cidade, para os anos de 2002, 2009 e 2016 e, então, submetida à verificação de correlação espacial. Ademais, o primeiro ano do estudo coincide ao início da disponibilidade dos dados, enquanto os demais são 
períodos seguintes às crises de 2008 e 2015. Além disso, o último ano corresponde aos dados mais recentes disponíveis no momento da execução deste trabalho.

\section{Indústria e seu papel na economia: contribuições teóricas e empíricas selecionadas}

Inicialmente, nesta seção, discute-se o marco teórico internacional e nacional versando sobre concentração industrial, o papel da indústria na economia e no crescimento e da desindustrialização. $O$ ponto de partida ocorre com estudos publicados na Inglaterra no final do século XIX e no início do século XX em que Marshall (1898) utilizou o termo "distrito industrial" para tratar sobre a concentração de empresas em um local.

Ao fim da década de 50 do século passado, Kaldor (1957) destacou o setor industrial como aquele com a maior capacidade de gerar emprego, de aumentar a renda per capita e de estimular o avanço da produtividade. O dinamismo da indústria está alicerçado nos rendimentos de escala crescentes, no progresso tecnológico existente nessa área, nas externalidades produzidas e no desdobramento da cadeia produtiva. Outros setores, como os produtores de commodities, não possuem o mesmo dinamismo, pois utilizam tecnologias com menor grau de intensidade.

Para autores como Solow (1956), entretanto, a indústria não possui papel explícito no crescimento econômico de longo-prazo. Em sua teoria, o produto provém da combinação entre capital e trabalho e o crescimento ao longo do tempo deve-se à formação de poupança e avanços tecnológicos, sem fazer distinção de setores.

Para Langoni (1976), crescimento econômico é em essência um processo de realização de ganhos de produtividade. Há três fontes de crescimento que considera relevantes. A primeira delas corresponde às economias de escala, que se refletem em reduções substanciais nos custos a partir da ampliação da produção. O custo médio cai e os fatores já existentes são utilizados de forma mais eficiente. Todavia, no longo prazo, os ganhos de produtividade dependem de melhorias tecnológicas:

Em segundo lugar, há os aumentos de produto oriundos da realocação dos investimentos em capital físico e humano. Em economias de mercado, há uma tendência para que os fatores de produção sejam remunerados conforme sua contribuição para o produto, ou seja, pela sua produtividade. Há um estímulo natural para migração de fatores de mesmas características para onde há maiores remunerações. Contudo, existem imperfeições que impedem que os diferenciais de 
produtividade não sejam eliminados.

A terceira fonte é a das externalidades. Mesmo que houvesse uma forma que fosse possível medir correta e precisamente o crescimento de todos os fatores, ainda assim, haveria uma parcela não explicada.

O processo de crescimento econômico, de acordo com Conceição (2008), é o resultado da interação entre a mudança institucional e tecnológica, mas compreender o processo de desenvolvimento requer uma investigação das formas que comportam seu avanço de maneira historicamente distinta tanto das mudanças tecnológicas, quanto das características das firmas ou das instituições influenciam padrões específicos de desenvolvimento.

O desenvolvimento, para Schumpeter (1984), é definido pela realização de novas combinações que geram um estado de desequilíbrio no sistema econômico, efetivado de duas formas: (i) novas empresas que geralmente começam a produzir no lado das antigas e (ii) pelo emprego de outros recursos de formas variadas. A inovação, para o autor, nada mais é que a realização dessas novas combinações.

No fim do século XX, autores como Rowthorn e Ramaswany (1999) debatem acerca dos impactos do processo de desindustrialização, que segundo eles ocorre à medida que a participação do emprego industrial em economias avançadas decai de forma contínua. Tregenna (2009) ampliou este conceito incluindo a diminuição do valor agregado industrial em proporção do PIB.

\section{Evolução histórica e evidências empíricas para a economia brasileira}

Logo após a II Guerra Mundial (1939-45), o pensamento oriundo da Comissão Econômica para América a América Latina e Caribe (CEPAL) pauta o debate sobre o processo de industrialização. A atividade industrial estaria ligada ao fomento da atividade primária e esta, ao contrário, não possuiria o poder de estimular a atividade industrial (CURADO, 2013).

Prebisch (1949), um dos autores ligados à CEPAL, desenvolveu uma abordagem teórica sólida em defesa da industrialização como promotora do desenvolimento. Para o autor, a divisão internacional do trabalho entre centro e periferia promoveria ao longo do tempo uma deterioração dos termos de troca entre as regiões. Nos países centrais (conjunto das economias industrializadas), haveria uma estrutura de mercado oligopolizada e com grande poder de barganha dos sindicatos. Com isso, os preços dos produtos possuíam forte resistência à baixa, 
impedindo quedas bruscas até mesmo em períodos de recessão global. Já os países periféricos (fornecedores das matérias primas, dos insumos e dos produtos agrícolas), atuavam num mercado competitivo e de maior flutuação de preços. Dessa forma, seria necessária uma quantidade maior de produtos básicos exportados para obter a mesma quantidade de produtos industrializados. Contudo, devido a elasticidade-renda da demanda dos produtos básicos ser menor que a dos produtos industrializados não era possível exportar mais produtos. Nesse contexto, os períodos de expansão das economias periféricas gerariam desequilíbrios comerciais insustentáveis de longo prazo. A forma de superar o subdesenvolvimento viria da redefinição das relações comerciais. A industrialização seria o meio para superar a restrição ao crescimento dos países periféricos.

Furtado (1968) realiza a defesa da industrialização a partir de dois argumentos: contenção do processo inflacionário e redução da demanda externa enquanto fator dinâmico da economia. O primeiro fator destaca que a inflação brasileira dos anos cinquenta do século $X X$ estava associada a um aumento de demanda, oriunda do aumento da renda monetária do setor exportador. 0 crescimento da oferta via industrialização seria importante então para ajustar oferta e demanda. O segundo trata do impacto do processo de industrialização em reduzir a importância do cenário externo para a realização dos investimentos imprescindíveis para a geração de emprego e a sustentação do ritmo de ampliação do produto brasileiro. Ao tratar sobre desenvolvimento econômico, Furtado (1961) escreve que esse consiste no ingresso de novas combinações de fatores de produção que tendem a incrementar a produtividade do trabalho, justamente as atividades industriais.

Conforme Carvalho e Silva (2008), a abertura comercial do início dos anos 1990 iniciou um processo de desindustrialização de economias subdesenvolvidas, inaptas a enfrentar a concorrência internacional. O processo de desindustrialização prejudicou também o agronegócio, pois diminuiu o valor das exportações de produtos manufaturados de origem agrícola enquanto cresceu os de produtos básicos.

Salienta-se, ainda, que o termo desindustrialização não está automaticamente ligado a uma volta de produtos primários à pauta exportadora. É possível que haja uma desindustrialização positiva. Seria o caso de a participação da indústria no emprego e no valor adicionado se reduzissem em face a uma transferência ao exterior das atividades mais intensivas em trabalho ou de menor valor adicionado. 
Esse processo de desindustrialização é tido como favorável se vier acompanhado de um aumento da participação de produtos com alto teor tecnológico e de valor agregado na pauta exportadora. Por outro lado, ela será negativa se a desindustrialização estiver associada à descoberta de recursos naturais escassos num determinado país ou região capaz de elevar a taxa real de câmbio. Como consequência, poderia ocorrer uma volta de produtos primários na pauta de exportações, de produtos de baixo valor adicionado ou, ainda, de baixo valor tecnológico (BRESSER-PEREIRA, 2007).

Para Oreiro e Feijó (2010), o pensamento heterodoxo evidencia que a indústria, principal fonte dos retornos crescentes de escala, seria indispensável para sustentar o crescimento no longo-prazo e a principal difusora do progresso tecnológico. Portanto, um processo de desindustrialização gera impactos negativos no potencial de crescimento de longo-prazo, pois diminui a geração de retornos crescentes e o ritmo de progresso técnico, a depender do estágio da economia. Mesmo que haja crescimento industrial, essa expansão não pode ser tomada como argumento da inexistência de desindustrialização. Para os autores, este processo ocorre a partir do momento em que o setor industrial perde importância como fonte geradora de empregos ou/e de valor adicionado à economia.

Contudo, segundo Hirutaka e Sarti (2015) ,os limites e as possibilidades do desenvolvimento industrial brasileiro necessitam de aprofundamento, ainda que 0 debate sobre a desindustrialização tenha cooperado para destacar a importância da indústria para o desenvolvimento econômico. O motivo seria a falta de consideração adequada das transformações que ocorreram, principalmente em relação ao acirramento da concorrência mundial e à reorganização das grandes empresas transnacionais. A seguir discutem-se alguns estudos empíricos selecionados sobre o tema indsutrialização, desindustrialização, emprego e localização no Brasil.

Cruz e Santos (2011) utilizaram desagregação geográfica do nível de microrregiões para estudar a dinâmica do emprego industrial no Brasil entre 1990 e 2009. Verificaram a perda da importância da indústria de transformação no emprego total e no valor agregado do PIB e, em termos espaciais, existem evidências de desconcentração industrial. Mas algumas regiões apresentaram ganho de relevância industrial, contudo parece estar ligado a indústrias menos avançadas tecnologicamente. O conteúdo tecnológico, no entanto, continua vinculado às regiões industriais consolidadas, apesar delas terem perdido importância.

De acordo com Morceiro e Guilhoto (2019), com dados do IBGE de 1970 a 
2016 e a participação dos setores de manufatura no PIB brasileiro, os autores afirmam que houve desindustrialização com intensidades e períodos distintos no Brasil. Em relação aos setores manufatureiros intensivos em trabalho, concluiu-se que a desindustrialização foi normal. Já em relação aos setores intensivos em conhecimento e tecnologia foi prematura e espera-se efeitos negativos para o desenvolvimento da ciência e tecnologia futura do país.

Em resumo, esta seção tratou que os retornos provenientes dos investimentos do setor industrial são, em parte ou no todo, maiores daqueles verificados nos demais. O setor secundário na medida que é mais produtivo, tornase fonte de crescimento, às vezes entendido como sinônimo de desenvolvimento. $A$ desindustrialização de um país pode ter impactos negativos, uma vez que perde a motriz da inovação tecnológica, da geração de empregos e de renda.

\section{Base de dados}

Este trabalho contou com dados sobre, valores produzidos, valores exportados e empregos. Foram coletadas seis informações entre os anos de 2002 a 2016 da atividade econômica de cada município do estado de Santa Catarina. O Quadro 1 reúne o nome de cada variável com sua respectiva unidade de grandeza e fonte.

Quadro 1 - Identificação e descrição das variáveis

\begin{tabular}{|c|c|c|c|}
\hline Variável & Descrição & Unidade & Fonte \\
\hline VAl & $\begin{array}{l}\text { Valor Adicionado Industrial - valor } \\
\text { adicionado bruto a preços } \\
\text { correntes da indústria }\end{array}$ & mil reais & $\begin{array}{l}\text { Instituto Brasileiro de Geografia e } \\
\text { Estatística (IBGE) em Produto } \\
\text { Interno Bruto dos Municípios. }\end{array}$ \\
\hline VAT & 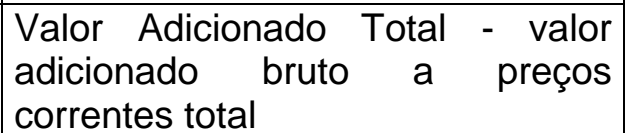 & mil reais & $\begin{array}{l}\text { IBGE em Produto Interno Bruto } \\
\text { dos Municípios. }\end{array}$ \\
\hline$X I$ & $\begin{array}{l}\text { Exportações Industriais - valor free } \\
\text { on board (FOB) das exportações } \\
\text { de produtos industrializados }\end{array}$ & $\begin{array}{c}\text { dólares } \\
\text { americanos }\end{array}$ & $\begin{array}{l}\text { Ministério da Indústria, Comércio } \\
\text { Exterior e Serviços (MDIC) em } \\
\text { Estatísticas do Comércio Exterior } \\
\text { do Brasil (ComexStat). }\end{array}$ \\
\hline$X T$ & $\begin{array}{l}\text { Exportações Totais - valor FOB } \\
\text { das exportações totais }\end{array}$ & $\begin{array}{c}\text { dólares } \\
\text { americanos }\end{array}$ & $\begin{array}{l}\text { MDIC em Estatísticas do } \\
\text { Comércio Exterior do Brasil } \\
\text { (ComexStat). }\end{array}$ \\
\hline El & $\begin{array}{l}\text { Emprego Industrial - número de } \\
\text { empregos formais no setor } \\
\text { industrial }\end{array}$ & Frequência & $\begin{array}{l}\text { Ministério do Trabalho e Emprego } \\
\text { (MTE) em Relação Anual de } \\
\text { Informações Sociais (RAIS). }\end{array}$ \\
\hline$E T$ & $\begin{array}{l}\text { Emprego Total - número de } \\
\text { empregos formais totais }\end{array}$ & Frequência & $\begin{array}{l}\text { MTE em Relação Anual de } \\
\text { Informações Sociais (RAIS). }\end{array}$ \\
\hline
\end{tabular}

Fonte: Elaborado pelos autores. 


\section{Elementos de um índice de industrialização e a Análise de Componentes Principais (PCA)}

Foram escolhidos três indicadores produtivos, variando entre zero e um, capazes de captar características de uma aglomeração. Dessa forma, define-se inicialmente os pesos: (1) Peso do Valor Adicionado Industrial ( $\left.P V A I_{i}\right)$, divisão entre o Valor Adicionado Industrial da cidade $i$ (VAli) e o Valor Adicionado Total (VATi) desse local; (2) Peso do Emprego Industrial ( $P E \mathrm{l}_{\mathrm{i}}$ ), razão entre os Empregos Industriais $\left(\mathrm{El}_{\mathrm{i}}\right)$ da cidade $i$ com o respectivo Emprego Total $\left(\mathrm{ET}_{\mathrm{i}}\right)$; (3) Peso de Exportações Industriais $\left(\mathrm{PXI}_{\mathrm{i}}\right)$, divisão entre as Exportações Industriais $\left(\mathrm{Xl}_{\mathrm{i}}\right)$ da cidade $i$ por suas Exportações Totais $\left(X \mathrm{~T}_{\mathrm{i}}\right)$.

$$
\begin{aligned}
& P V A I_{i}=V A I_{i} / V A T_{i} \\
& P E I_{i}=E I_{i} / E T_{i} \\
& P X I_{i}=X I_{i} / X T_{i}
\end{aligned}
$$

Os três pesos combinados linearmente fornecem os parâmetros para elaborar um único indicador de concentração da atividade industrial, ora chamado de Índice Municipal Industrial (IMI). Tão logo cada um dos três índices capta de forma distinta o poder de aglomeração, foram calculados pesos específicos para cada indicador, representado pelos $\theta$ 's (CROCCO et al., 2006):

$$
I M I_{i}=\theta_{1} P V A I_{i}+\theta_{2} P E I_{i}+\theta_{3} P X I_{i}
$$

Para chegar nos pesos adequados da Equação (4), e consequentemente no índice proposto, são utilizadas técnicas de análises multivariadas que servem tanto para a construção ou análise de indicadores compostos (OECD, 2008). Dentre as opções existentes, utilizou-se a PCA, cujo objetivo é explicar a variância observada nos dados através de uma combinação linear entre eles. Utiliza-se a matriz de correlação das variáveis que, dessa forma, possibilita que se calcule o percentual da variância da dispersão total que é explicado por cada uma das três variáveis estabelecidas (CROCCO et al., 2006).

De acordo com Crocco et al. (2006), a análise de componentes principais pode ser feita com $n$ variáveis $X_{1}, X_{2}, \ldots, X_{n}$ cujas combinações lineares produzem os componentes $Z_{1}, Z_{2}, \ldots, Z_{n}$ :

$$
Z_{i}=a_{i 1} X_{1}+a_{i 2} X_{2}+\ldots+a_{i n} X_{n}
$$

Os componentes oscilam entre os indivíduos da amostra, sujeitos à condição: 


$$
a_{i 1}{ }^{2}+a_{i 2}{ }^{2}+\ldots+a_{i n}{ }^{2}=1
$$

A matriz de covariância das variáveis é usada tanto para encontrar as variâncias de cada componente quanto os coeficientes das combinações lineares. Os autovalores dessa matriz representam as variâncias dos componentes principais, no qual os coeficientes $a_{i 1}, a_{i 2}, \ldots$, $a_{i n}$ são os autovetores associados. Como toda matriz de variância, ela é simétrica e tem o seguinte formato (CROCCO et al., 2006):

$$
C=\left[\begin{array}{ccc}
c_{11} & \cdots & c_{1 n} \\
\vdots & \ddots & \vdots \\
c_{n 1} & \cdots & c_{n n}
\end{array}\right]
$$

Vale destacar que a soma dos autovalores é igual à soma dos elementos da diagonal principal da matriz $C$, ou ainda, ao traço dessa matriz, em que $\lambda_{i}$ representa os autovalores - ou variância - de cada elemento i (CROCCO et al., 2006):

$$
\lambda 1+\lambda 2+\ldots+\lambda n=c_{11}+c_{22}+\ldots+c_{m n}
$$

A soma das variâncias de todas as variáveis originais é igual à de todos os componentes, pois $c_{i i}$ é tanto a variância de $X_{i}, \lambda_{i}$ e $Z_{i}$. Assim, garante-se que a variância total dos dados é levada em conta (CROCCO et al., 2006).

De acordo com a matriz de variância, é possível conhecer a importância de cada uma das variáveis (no caso concreto PVAI, PEI e $P X I$ ) para a explicação da variância total da amostra. A Tabela 1 representa a diagonal principal da Matriz $\mathrm{C}$, estratificada pela variância relativa de cada componente e pelo valor acumulado

\begin{tabular}{|c|c|c|}
\hline Componente & Variância explicada pelo componente & Variância acumulada \\
\hline 1 & $\beta_{1}$ & $\beta_{1}$ \\
\hline 2 & $\beta_{2}$ & $\beta_{1}+\beta_{2}$ \\
\hline 3 & $\beta_{3}$ & $\beta_{1}+\beta_{2}+\beta_{3}(=100 \%)$ \\
\hline
\end{tabular}
(CROCCO et al., 2006):

Tabela 1 - Autovalores da matriz de variância

Fonte: Crocco et al. (2006).

Em sequência, a Tabela 2 mostra os valores da matriz de correlação das variáveis cuja importância é o cálculo da participação relativa de cada um dos indicadores em cada um dos componentes, com o intuito de demonstrar a importância das variáveis nos componentes (CROCCO et al., 2006): 
Tabela 2 - Autovetores da matriz de correlação.

\begin{tabular}{llll}
\hline Índice de Concentração & Componente 1 & Componente 2 & Componente 3 \\
\hline PVAI & $\alpha_{11}=1$ & $\alpha_{12}$ & $\alpha_{13}$ \\
$P E I$ & $\alpha_{21}$ & $\alpha_{22}=1$ & $\alpha_{23}$ \\
$P X I$ & $\alpha_{31}$ & $\alpha_{32}$ & $\alpha_{33}=1$ \\
\hline
\end{tabular}

Fonte: Elaboração própria com base em Crocco et al. (2006).

Para obter a importância relativa, inicialmente é calculada a soma dos módulos de cada vetor coluna, que representa individualmente cada componente (CROCCO et al., 2006):

$$
\begin{aligned}
& C_{1}=\left|\alpha_{11}\right|+\left|\alpha_{21}\right|+\left|\alpha_{31}\right| \\
& C_{2}=\left|\alpha_{21}\right|+\left|\alpha_{22}\right|+\left|\alpha_{32}\right| \\
& C_{3}=\left|\alpha_{31}\right|+\left|\alpha_{32}\right|+\left|\alpha_{33}\right|
\end{aligned}
$$

Posteriormente, cada valor das células da Tabela 2 é dividido pelo total de seu respectivo componente, como demonstrado na Tabela 3 (CROCCO et al., 2006):

Tabela 3 - Participação relativa dos autovetores da matriz de correlação.

\begin{tabular}{llll}
$\begin{array}{l}\text { Índice de } \\
\text { Concentração }\end{array}$ & \multicolumn{1}{c}{ Componente 1 } & \multicolumn{1}{c}{ Componente 2 } & \multicolumn{1}{c}{ Componente 3 } \\
\hline PVAli & $\alpha_{11}^{\prime}=\left|\alpha_{11}\right| / C_{1}$ & $\alpha_{12}^{\prime}=\left|\alpha_{12}\right| / C_{2}$ & $\alpha_{13}^{\prime}=\left|\alpha_{13}\right| / C_{3}$ \\
PEli & $\alpha_{21}^{\prime}=\left|\alpha_{21}\right| / C_{1}$ & $\alpha_{22}^{\prime}=\left|\alpha_{22}\right| / C_{2}$ & $\alpha_{23}^{\prime}=\left|\alpha_{23}\right| / C_{3}$ \\
PXI & $\alpha_{31}^{\prime}=\left|\alpha_{31}\right| / C_{1}$ & $\alpha_{32}^{\prime}=\left|\alpha_{32}\right| / C_{2}$ & $\alpha_{33}^{\prime}=\left|\alpha_{33}\right| / C_{3}$ \\
\hline
\end{tabular}

Fonte: Elaborado pelos autores com base em Crocco et al. (2006).

Como apontado, os $\beta$ 's da Tabela 1 fornecem a variância dos componentes; os $\alpha_{i j}^{\prime}$ da Tabela 4 a importância de cada variável dentro dos componentes. Assim, a Tabela 5 indica o peso final de cada $\theta$ a ser utilizado na Equação 4, constituído pela soma dos produtos dos $\alpha^{\prime}{ }_{i j}$ pelos seus $\beta$ 's correspondentes:

Tabela 4 - Pesos finais do Índice Municipal Industrial (IMli).

\begin{tabular}{cc}
\hline Índice de Concentração & Pesos \\
\hline PVAli & $\theta_{1}=\alpha_{11}^{\prime} \beta_{1}+\alpha_{12}^{\prime} \beta_{2}+\alpha_{13}^{\prime} \beta_{3}$ \\
PEli & $\theta_{2}=\alpha_{21}^{\prime} \beta_{1}+\alpha_{22}^{\prime} \beta_{2}+\alpha_{23}^{\prime} \beta_{3}$ \\
PXI & $\theta_{3}=\alpha_{31}^{\prime} \beta_{1}+\alpha_{32}^{\prime} \beta_{2}+\alpha_{33}^{\prime} \beta_{3}$ \\
\hline
\end{tabular}

Fonte: Elaborado pelos autores com base em Crocco et al. (2006). 


\section{Análise exploratória de dados espaciais univariada}

Após a construção do IMI utilizou-se análise espacial, com estatísticas de autocorrelação espacial global e local, em especial a estatística Local de Moran para identificar a formação de grupos. O início da avaliação é dado pela determinação espacial da matriz de pesos, cuja noção está baseada na contiguidade dos polígonos. Existem duas formas comuns de abordagem de pesos: rainha (usada neste trabalho) e torre. (ANSELIN, 2018). A estatística de Moran's I é o indicador de autocorrelação espacial global mais comum. Em suma, é uma estatística de produto cruzado entre uma variável e sua defasagem espacial, com a variável expressa em desvios de sua média. Para uma observação no local $i$, isto é expresso como $z_{i}=x_{i}$ $\bar{x}_{i}$, em que $\bar{x}_{i}$ é a média da variável $x$. A Equação 12 descreve esta estatística, em que $w_{i j}$ representa os elementos da matriz de pesos espacial, $\mathrm{S}_{0}=\sum_{i} \sum_{j} w_{i j}$ a soma de todos os pesos e no número de observações (ANSELIN, 2018).

$$
I=\frac{\sum_{i} \Sigma_{j} w_{i j} z_{i} z_{j} / s_{0}}{\sum_{i} z_{i}^{2} / n}
$$

A hipótese nula da estatística é que o espaço seja aleatório e a distribuição pode ser derivada a partir de uma premissa de normalidade, em que cada valor é igualmente provável de ocorrer em qualquer local. Ou ainda, é possível uma derivação computacional baseada em permutações. Uma distribuição de referência é calculada baseada na hipótese nula de espaço aleatório através de uma permutação randômica dos valores observados de cada local (ANSELIN, 2018).

Já a estatística Local de Moran busca identificar aglomerações locais e também outliers. Esta estatística opera da mesma forma que o Moran's I global, exceto que as permutações são executadas para cada observação por vez. Na Equação 13 a seguir, $z$ representa os desvios em relação à média; o escalar $c$ é o mesmo para todos os locais e não atua no cálculo da significância; a última parte é obtida por um método de permutação condicional em que cada $z_{i}$ é mantido fixo e os valores $z$ restantes são aleatoriamente permutados para produzir uma distribuição de referência para a estatística. O resultado é um pseudo p-valor para cada localidade, que pode então ser usado para avaliar a significância (ANSELIN, 2018).

$$
c . z_{i} \sum_{j} w_{i j} z_{j}
$$

A partir dos resultados observados, este trabalho contou com a permutação 
padrão cujo valor é 999 e p-valor de 0,05 para avaliar as estatísticas que permitem agrupar as localidades significativas que estão acima ou abaixo da média. Além disso, atribuiu-se uma indicação do tipo de associação espacial, com base na localização do valor e na sua defasagem espacial no gráfico de dispersão de Moran (Moran Scatterplot). A classificação da autocorrelação espacial em quatro tipos inicia a conexão entre a autocorrelação global e local. $O$ centro do gráfico equivale à média, e à medida que os pontos se afastam dele forma-se uma ideia de associação espacial dividida em alto-alto, baixo-baixo, baixo-alto e alto-baixo. É importante destacar que enquanto o gráfico de dispersão de Moran classifica todos os elementos em relação à média, a estatística local seleciona, entre esses valores, apenas os que possuem significância. Dessa forma, os clusters são identificados pela reagrupação dos elementos em um Indicador Local de Associação Espacial (LISA) em que cada localidade passa a ser atribuída com um valor de 0 a 4 , em que, respectivamente, correspondem à associação não-significante, alto-alto, baixo-baixo, baixo-alto e, por fim, alto-baixo (ANSELIN, 2018).

\section{Estatísticas descritivas}

Nesta seção é apresentado um panorama das informações coletadas a nível municipal e das transformações as quais os dados foram submetidos.

De acordo com o Gráfico 1, O Estado registrou aumento real do Valor Adicionado Total (VATr) entre os anos de 2002 a 2016. Embora tenha recuado nas últimas duas medições, o crescimento, em média, foi de $4,61 \%$ ao ano em Santa Catarina. O Peso do Valor Adicionado Industrial oscilou na faixa de 0,31 a 0,35 , de 2002 a 2013. Embora a indústria tenha crescido em termos reais, a importância relativa declinou pois em 2016 a participação da indústria foi a menor registrada na série, cujo valor é de 0,27. Ainda assim, está acima do peso registrado nacionalmente, de 0,21 . No cenário nacional, o PIB cresceu a $3,5 \%$ ao ano entre 2000 e 2012 e o ganho de produtividade entre os trabalhadores explicou mais de 50\% do crescimento (BARBOSA FILHO; PESSÔA, 2014). 
Gráfico 1 - Valor Agregado Total Catarinense e o Peso do Valor Agregado Industrial estadual e nacional - 2002 a 2016

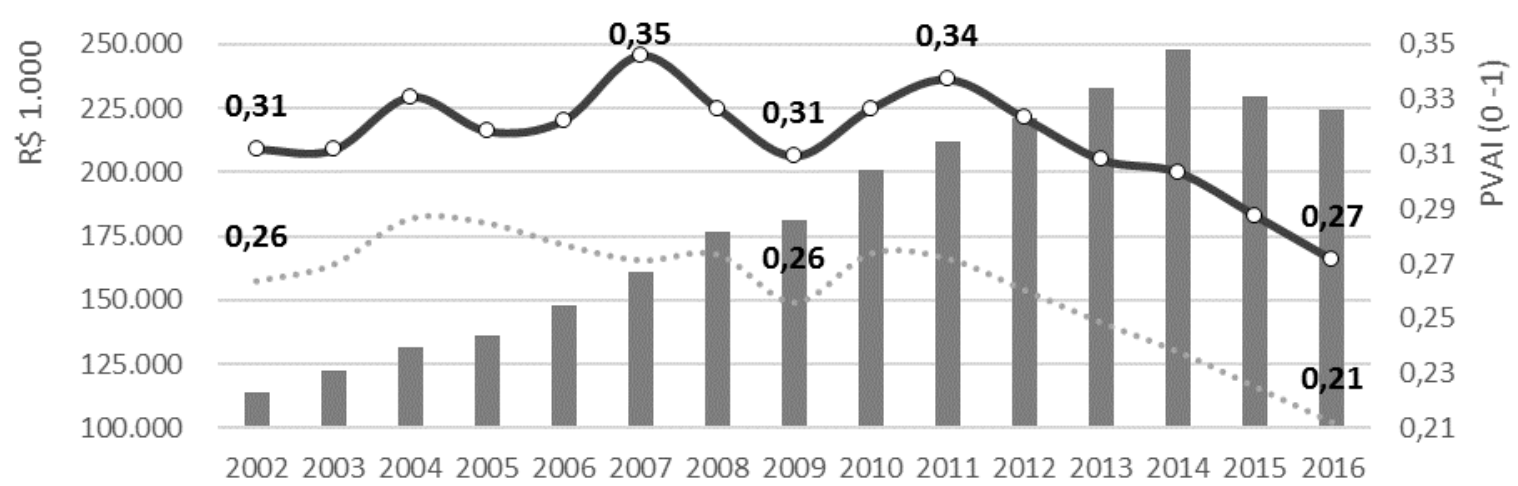

200220032004200520062007200820092010201120122013201420152016

VATr $(R \$ \$ 1.000) \quad \longrightarrow$ PVAI-SC $\quad \cdots . .$. PVAI-BR

Fonte: Elaborado pelos autores com dados do IBGE.

Notas: Eixo principal: valores agregados de todos os setores corrigidos pelo IPCA $(2017=1)$.

Eixo secundário: peso do valor adicionado industrial.

A crise econômica e política instalada no país em 2015 impôs grandes desafios à estrutura produtiva nacional, mas a perda da participação do valor adicionado industrial demonstra sinais de quedas após 2007. Naquele ano, o PVAI catarinense chegou ao seu valor máximo no período analisado $(0,35)$ e inicia sua queda até 2009 (0,31). Há uma pequena recuperação até $2011(0,34)$, contudo não alcança os valores de 2007. Desde então, a representatividade do valor adicionado industrial recua de forma contínua, alcançando seu menor nível em $2016(0,27)$ (Gráfico 1) (FIESC, 2017).

Já o Gráfico 2, trata do número de Empregos Totais em Santa Catarina cujo crescimento médio é de $3,69 \%$ ao ano. Os dados corroboram os resultados de Barbosa Filho e Pessôa (2014) que apontam expansão de pessoal ocupado em nível nacional entre 2000 e 2012. O peso da indústria perdeu relevância nos empregos totais (Gráfico 2), em 2002, o setor industrial continha $35 \%$ dos vínculos empregatícios, caindo para $30 \%$ em 2017 - no Brasil é de $20 \%$ e 17\%, respectivamente. Para a FIESC (2015), a causa provável do fortalecimento do número de empregos totais se deve pelo aumento das contratações ou então maior volume de estabelecimentos declarando suas informações. 
Gráfico 2 - Empregos Totais em Santa Catarina e peso do setor industrial estadual e nacional - 2002 a 2017

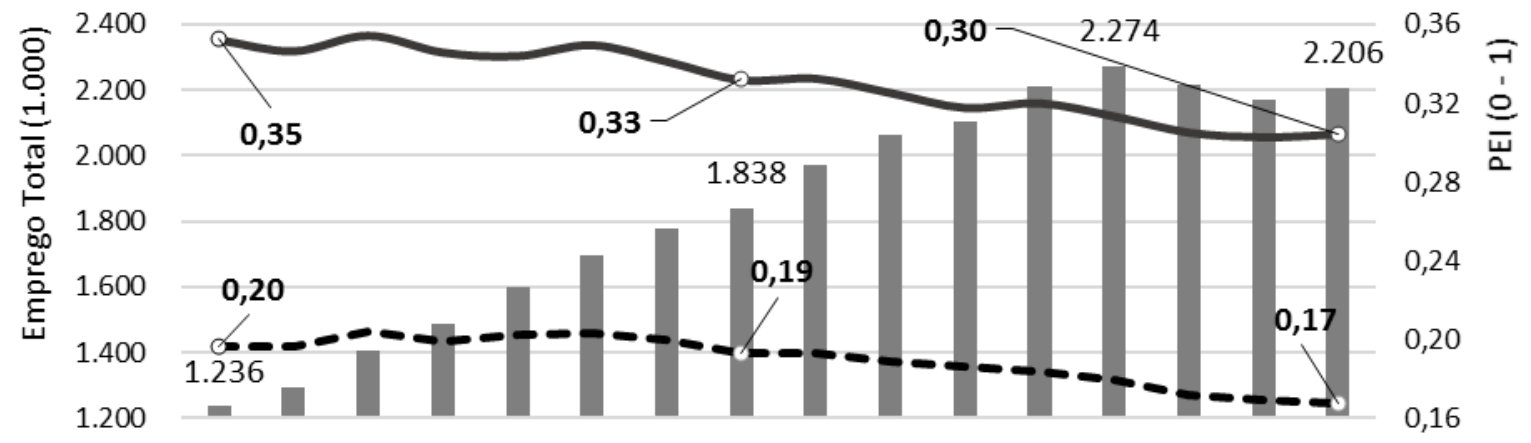

2002200320042005200620072008200920102011201220132014201520162017

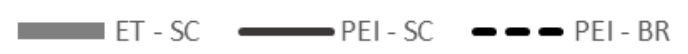

Fonte: Elaborado pelos autores com dados do MTE.

Notas: Eixo principal: emprego total a cada um mil.

Eixo secundário: peso do emprego industrial.

Como se pode perceber, a participação da indústria na economia declinou em relação ao PIB desde 2002, podendo ser compatível com um cenário de desindustrialização conforme conceituado por Rowthorn e Ramaswany (1999), segundo os quais a desindustrialização é o processo pelo qual a participação do emprego industrial em economias avançadas decai de forma contínua.

A análise dos dados também dá indícios de desindustrialização a partir do conceito na concepção de Tregenna (2009), pois se verificou a perda do valor agregado industrial em proporção do Produto Interno Bruto - em 2002 a indústria contribuía com 31\% do PIB, reduzindo-se a 27\% em 2016.

Conforme o Gráfico 3, as exportações aumentaram em termos nominais de USD \$ 3,6 bilhões de dólares em 2002 para USD \$14,1 bilhões em 2018, verificandose um acréscimo médio de 8,29\% a.a.. Enquanto isso, as exportações da indústria registraram crescimento de 5,28\% no mesmo período e os produtos básicos de $11,29 \%$ a.a.. O peso relativo da pauta industrial cedeu espaço aos produtos básicos cuja representação era de 61\% em 2002 e diminuiu 23 pontos percentuais até 2018.

A partir de 2012 a importância relativa das manufaturas voltou a crescer, obtendo em 2015 um peso de 48\%. Destaca-se, contudo, que este aumento se deu muito mais devido a uma retração dos produtos básicos, aproximadamente $24 \%$ entre 2014 e 2015, que um aumento das manufaturas. 
Gráfico 3 - Exportações catarinenses e peso das exportações industriais entre 2002 e 2018.

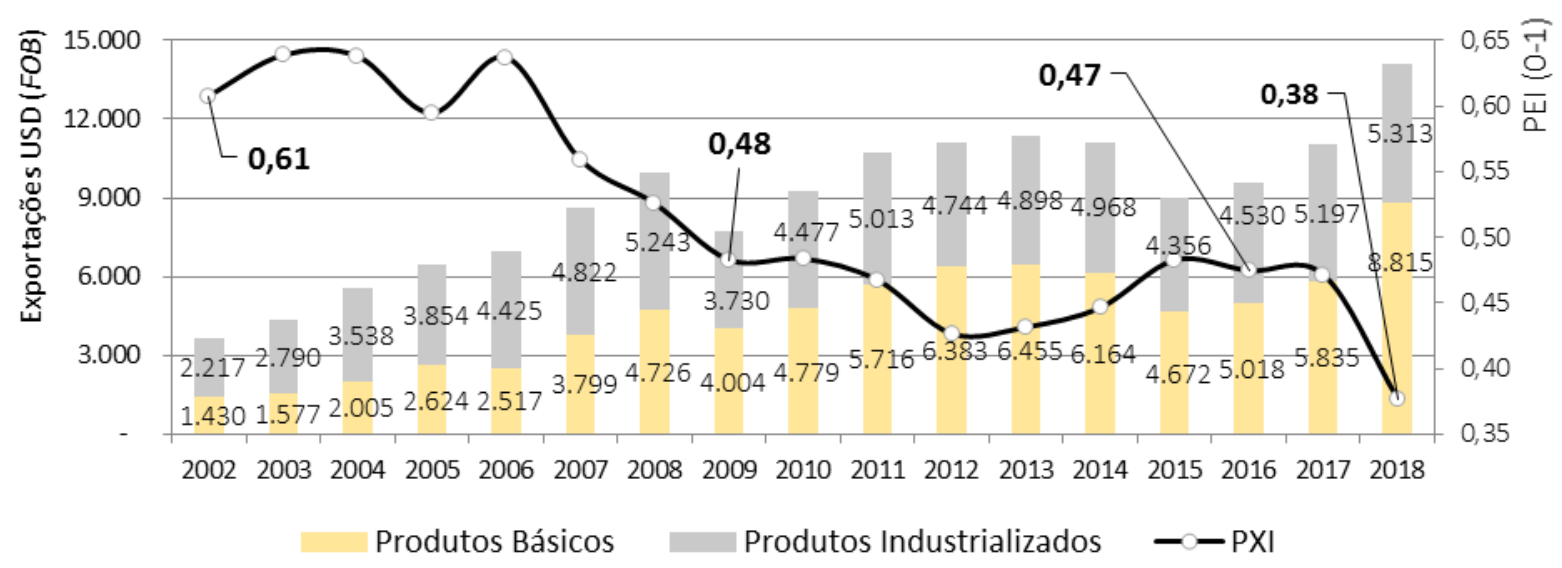

Fonte: Elaborado pelos autores com dados do MDIC.

Notas: Eixo principal: exportações totais a cada USD 1.000.000 (FOB).

Eixo secundário: peso das exportações industriais.

As Operações Especiais estão ignoradas no gráfico. O maior valor do período é registrado em 2011 e representa $0,09 \%$ de todas as exportações do Estado.

Entre 2002 e 2016, inclusive, as exportações de produtos básicos, além de mais representativas na pauta em comparação aos produtos industrializados, cresceram de forma mais acelerada. Há, contudo, uma concentração estável em carnes e miudezas comestíveis, contribuindo com cerca de $70 \%$ das exportações de básicos do período. As exportações industriais são mais diversificadas que as de produtos básicos. Um ponto positivo é a presença de produtos manufaturados com maior valor agregado, produzidos principalmente nas Regiões Norte e Vale do Itajaí . (MDIC, 2019)

Os resultados corroboram as conclusões de Perobelli, Bastos e Oliveira (2017) para os anos de 1995 e 2009, em que os autores já haviam identificado queda em indicadores que apontam que o setor secundário tem perdido intensidade industrial no país.

Assim, é possível concluir que no estado, a participação da indústria na economia, tanto em valor adicionado quanto de empregos, vem perdendo peso desde 2002, agravando-se a partir de 2015, o que pode sugerir um cenário de desindustrialização. As exportações, apesar de seguirem a mesma tendência de queda, possuem produtos de alto valor agregado na pauta, que crescem tanto quanto as exportações totais ou mais, dependendo do produto exportado. 
Evolução e transformações do IMI em Santa Catarina entre 2002 e 2016 a partir da Análise de Componentes Principais

Nesta seção são avaliados os resultados da construção do IMI, de sua distribuição pelo Estado. A Tabela 5 reúne a importância dos pesos de PVAI, PEI e $\mathrm{PXI}$, ou seja dos respectivos $\theta$ 's, que se mostraram relativamente estáveis nos três anos.

Tabela 5 - Importância dos Pesos na Análise dos Componentes Principais

\begin{tabular}{ccccc}
\hline Ano & $\boldsymbol{\theta}_{1}-\boldsymbol{P V A I}$ & $\boldsymbol{\theta}_{2}-$ PEI & $\boldsymbol{\theta}_{3}-\boldsymbol{P X I}$ & $\Sigma$ \\
\hline 2002 & 0,29 & 0,26 & 0,45 & 1,00 \\
2009 & 0,27 & 0,28 & 0,45 & 1,00 \\
2016 & 0,28 & 0,26 & 0,46 & 1,00 \\
\hline
\end{tabular}

Fonte: elaborado pelos autores.

De acordo com a Erro! Fonte de referência não encontrada., a única média entre os pesos a aumentar nos três anos foi a do PEI enquanto o IMI declina entre 2002 e 2009, provavelmente em função da crise de 2007, mas eleva-se entre 2009 e 2016 e ultrapassa o valor inicial.

O IMI, por sua vez, permite ser ordenado e indicar as cidades segundo o grau de industrialização de acordo com suas estruturas produtiva. Conforme a Figura 1, o Vale e Norte Catarinense concentram os maiores índices. A distribuição pouco se alterou ao longo do período. Em 2002 e 2016 registraram-se 72 cidades com IMI superior a 0,622, com 4 cidades a menos em 2009. Com relação aos dados desta figura, a macrorregião do Vale do Itajaí está presente entre os quatro maiores índices em todos os anos. Já a macrorregião Oeste Catarinense reúne as cidades cujos valores do IMI foram os menores. 
Figura 1 - Distribuição espacial do IMI - Santa Catarina - 2002, 2009 e 2016
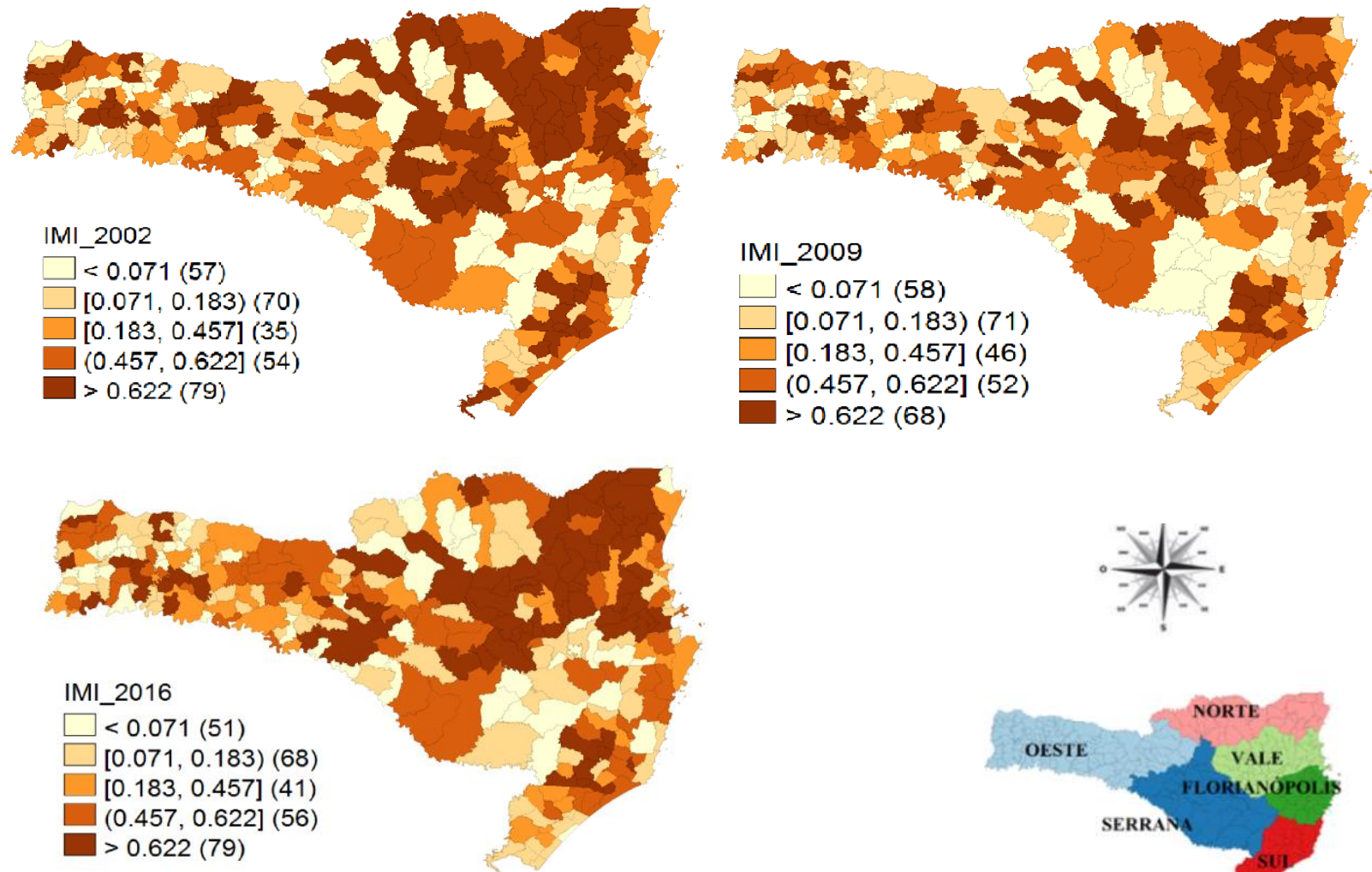

Fonte: elaborado pelos autores.

Nota: Imagem elaborada em GeoDa.

Figura 2 - Crescimento do IMI em Santa Catarina entre 2016 e 2002
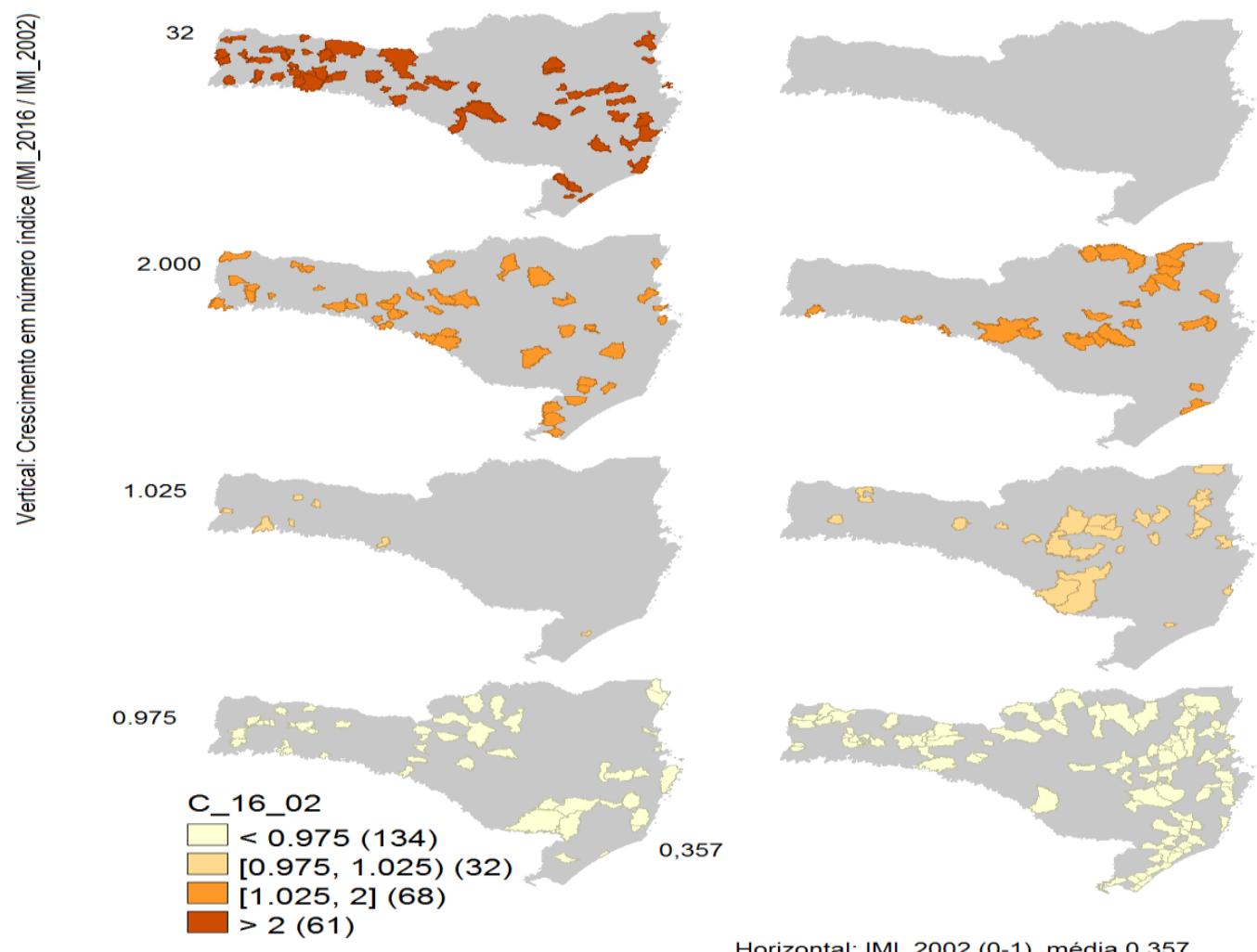

Horizontal: IMI_2002(0-1), média 0,357 
$\mathrm{Na}$ Figura 2, com o intuito de analisar o crescimento do IMI, este foi segmentado em quatro faixas no eixo vertical. A primeira, indica as cidades que tiveram redução maior que 2,5\%; a segunda, representa as cidades que oscilaram $2,5 \%$ acima ou abaixo dos seus valores em 2002; a terceira possui as cidades cujo IMI cresceu entre 2,5\% e 100\%; e, por último, as cidades que cresceram mais que 100\%. O eixo horizontal está separado pela média do IMI em 2002.

Verifica-se que entre as 5 cidades onde o IMI mais cresceu há, em média, 199 empregos registrados no setor industrial em 2016, enquanto nas 5 cidades em que ele mais diminuiu são 294. A média do Estado é de 2.926 empregos industriais por município (MTE, 2019).

A Tabela 6 reúne estas cidades e informa quais atividades industriais contribuíram para o aumento ou queda do IMI.

Tabela 6 - Maiores crescimentos e quedas do IMI em Santa Catarina entre os anos de 2002 e 2016

\begin{tabular}{|c|c|c|c|c|c|}
\hline $\begin{array}{l}\text { Fonte:elabo } \\
\text { Notaldedeagen }\end{array}$ & $\begin{array}{l}\text { radopelos autores. } \\
\text { n elabocradregiagra em GeoD }\end{array}$ & $\begin{array}{c}\text { IMI } \\
2002\end{array}$ & $\begin{array}{c}\text { IMI } \\
2016\end{array}$ & $\begin{array}{c}\text { Cresc } \\
(\%)\end{array}$ & Destaque (1) \\
\hline Bandeirante & Oeste Catarinense & 0,020 & 0,625 & $3078 \%$ & Madeira e Mobiliário \\
\hline Bombinhas & Vale do Itajaí & 0,030 & 0,508 & $1588 \%$ & Alimentos e Bebidas \\
\hline Paulo Lopes & Grande Florianópolis & 0,046 & 0,560 & $1117 \%$ & Alimentos e Bebidas \\
\hline Irani & Oeste Catarinense & 0,063 & 0,531 & $749 \%$ & Madeira e Mobiliário \\
\hline Arvoredo & Oeste Catarinense & 0,017 & 0,141 & $749 \%$ & Indústria Mecânica \\
\hline Imbituba & Sul Catarinense & 0,545 & 0,071 & $-87 \%$ & Exportações de Cerâmica \\
\hline Tunápolis & Oeste Catarinense & 0,534 & 0,066 & $-88 \%$ & $\begin{array}{l}\text { Exportação de preparações de prod. hortícolas, } \\
\text { de frutas ou de outras partes de plantas }\end{array}$ \\
\hline Calmon & Oeste Catarinense & 0,145 & 0,017 & $-88 \%$ & Madeira e Mobiliário \\
\hline Zortéa & Serrana & 0,134 & 0,016 & $-88 \%$ & Madeira e Mobiliário \\
\hline União do Oeste & Oeste Catarinense & 0,578 & 0,058 & $-90 \%$ & Exportações de móveis e mobiliários \\
\hline
\end{tabular}

Fonte: Elaborado pelos autores.

(1) Os destaques referem-se às atividades que impactaram no aumento no crescimento do IMI, no caso do crescimento ser positivo. No caso de diminuição do IMI, referem-se às atividades que auxiliaram na sua queda.

Analisando-se o o crescimento do IMI através das macrorregiões do Estado (Tabela 7), constata-se que no Oeste houve o maior aumento de sua média, 18,9\%. O IMI médio em em 2002 era de 0,26 e alcançou a marca de 0,31 em 2016. Ainda assim, continua sendo o menor do Estado, todavia aproximando-se da Serra. Já o Sul Catarinense obteve a maior queda, de 0,43 para 0,37. Verificou-se, portanto, transformação espacial e setorial da localização industrial no período analisado, com redução da hegemonia das regiões mais desenvolvidas. 
Tabela 7 - Média do IMI de acordo com as macrorregiões catarinenses em 2002 e 2016

\begin{tabular}{|c|c|c|c|}
\hline \multirow{2}{*}{ Região } & \multicolumn{3}{|c|}{ IMI } \\
\hline & 2002 & 2016 & Variação \\
\hline Grande Florianópolis... & 0,33 & 0,35 & $7,9 \%$ \\
\hline 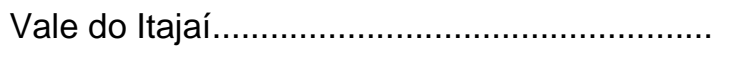 & 0,50 & 0,52 & $4,9 \%$ \\
\hline Sul Catarinense.................... & 0,43 & 0,37 & $-14,6 \%$ \\
\hline Serrana... & 0,34 & 0,32 & $-5,1 \%$ \\
\hline 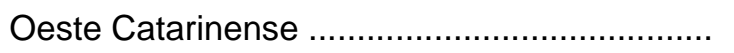 & 0,26 & 0,31 & $18,9 \%$ \\
\hline Norte Catarinense & 0,47 & 0,44 & $-7,1 \%$ \\
\hline
\end{tabular}

Fonte: Elaborado pelo autor.

Nota: Dados arredondados.

Em seguida, na Tabela 8, as macrorregiões foram reagrupadas de acordo com o tamanho da população de suas cidades.

Tabela 8 - IMI de acordo com a população e macrorregião no Estado de Santa Catarina nos anos de 2002 e 2016

\begin{tabular}{|c|c|c|c|c|c|c|c|}
\hline \multirow{2}{*}{$\begin{array}{l}\text { Segmentação em número de habitantes } \\
\text { e macrorregião }\end{array}$} & \multicolumn{3}{|c|}{$\begin{array}{l}\text { Média do IMI dos } \\
\text { municípios }\end{array}$} & \multicolumn{4}{|c|}{$\begin{array}{c}\text { Relação entre o VAI e o VAT do } \\
\text { Estado (PVAI) }\end{array}$} \\
\hline & 2002 & 2016 & $\begin{array}{l}\text { Variação } \\
(\%)\end{array}$ & 2002 & 2016 & $\begin{array}{l}\text { Variação } \\
\text { (p. p.) }\end{array}$ & $\begin{array}{l}\text { Variação } \\
(\%)\end{array}$ \\
\hline Até 10.000 habitantes........... & 0,26 & 0,28 & $9,3 \%$ & $2,1 \%$ & $2,1 \%$ & 0,0 & $1,8 \%$ \\
\hline Vale do Itajaí e Norte Catarinense.......... & 0,38 & 0,46 & $19,93 \%$ & $0,3 \%$ & $0,4 \%$ & 0,1 & $17,3 \%$ \\
\hline Sul Catarinense....................................... & 0,31 & 0,26 & $-15,67 \%$ & $0,2 \%$ & $0,3 \%$ & 0,0 & $14,8 \%$ \\
\hline Serrana... & 0,27 & 0,25 & $-7,64 \%$ & $0,2 \%$ & $0,1 \%$ & 0,0 & $-7,4 \%$ \\
\hline Oeste Catarinense.............................. & 0,22 & 0,25 & $15,88 \%$ & $1,3 \%$ & $1,2 \%$ & $-0,1$ & $-4,5 \%$ \\
\hline Grande Florianópolis........ & 0,21 & 0,22 & $6,52 \%$ & $0,1 \%$ & $0,1 \%$ & 0,0 & $13,9 \%$ \\
\hline De 10.001 a 50.000 habitantes....... & 0,48 & 0,49 & $2,2 \%$ & $8,3 \%$ & $8,6 \%$ & 0,3 & $3,5 \%$ \\
\hline Vale do Itajaí e Norte Catarinense... & 0,55 & 0,53 & $-3,42 \%$ & $3,4 \%$ & $4,0 \%$ & 0,6 & $17,9 \%$ \\
\hline 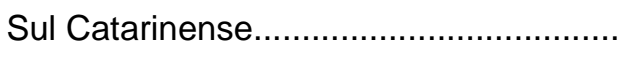 & 0,50 & 0,44 & $-12,44 \%$ & $1,7 \%$ & $1,5 \%$ & $-0,2$ & $-13,8 \%$ \\
\hline Serrana........................... & 0,52 & 0,51 & $-1,65 \%$ & $0,7 \%$ & $0,8 \%$ & 0,1 & $13,7 \%$ \\
\hline Oeste Catarinense............ & 0,36 & 0,46 & $25,67 \%$ & $2,1 \%$ & $1,8 \%$ & $-0,4$ & $-16,4 \%$ \\
\hline Grande Florianópolis.............................. & 0,44 & 0,57 & $29,14 \%$ & $0,4 \%$ & $0,6 \%$ & 0,2 & $47,3 \%$ \\
\hline Mais de 50.000 habitantes.......... & 0,52 & 0,47 & $-11,0 \%$ & $20,8 \%$ & $16,4 \%$ & $-4,4$ & $-21,0 \%$ \\
\hline Vale do Itajaí e Norte Catarinense.......... & 0,53 & 0,47 & $-12,50 \%$ & $14,7 \%$ & $10,7 \%$ & $-4,0$ & $-27,5 \%$ \\
\hline 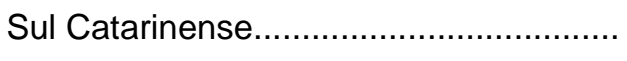 & 0,58 & 0,46 & $-20,81 \%$ & $1,7 \%$ & $1,4 \%$ & $-0,3$ & $-17,1 \%$ \\
\hline Serrana................... & 0,60 & 0,59 & $-0,92 \%$ & $0,6 \%$ & $0,5 \%$ & $-0,1$ & $-19,8 \%$ \\
\hline Oeste Catarinense................................... & 0,45 & 0,51 & $13,98 \%$ & $1,8 \%$ & $2,0 \%$ & 0,2 & $9,5 \%$ \\
\hline Grande Florianópolis......................... & 0,49 & 0,39 & $-19,29 \%$ & $1,9 \%$ & $1,9 \%$ & $-0,1$ & $-3,9 \%$ \\
\hline
\end{tabular}

Fonte: Elaborado pelos autores.

Nota: Dados numéricos arredondados.

As cidades com população de até 10.000 habitantes foram as quais o IMI mais cresceu entre 2002 e 2016 (9,3\%), principalmente no Vale, Norte e Oeste. 
Contudo, estas cidades não aumentaram suas participações industriais no VAT, ficando estáveis em 2,1\%. Já as cidades entre 10.001 e 50.000 mil habitantes tiveram ótimos desempenhos de crescimento no Oeste e Grande Florianópolis, com forte redução no Sul. Estas cidades pouco alteraram o quanto seu setor industrial contribuiu no VAT do Estado, passando de 8,3 a 8,6\%. A maior redução do IMI, todavia, está nas cidades com mais de 50.000 mil habitantes, cujo recuo foi de aproximadamente $11 \%$.

Embora a média do IMI das cidades do Norte tenha recuado aproximadamente $7 \%$, esta macrorregião em conjunto com o Vale concentra a maior parte do VAl do Estado, em particular nas cidades acima de 50 mil habitantes. Durante o período analisado, o PVAI destas duas regiões recuou mais de 4 pontos percentuais e representa o maior impacto na redução do PVAl estadual (Tabelas 7 e 8).

Conforme a Tabela 9, os setores industriais de Blumenau, Brusque, Jaraguá do Sul e Joinville representavam, em conjunto, 10,9\% do total do VAT catarinense em 2002 e recuaram para 7,0\% em 2016.

Tabela 9 - IMI das cidades com os maiores PVAl's em 2002 e 2016 - Santa Catarina

\begin{tabular}{|c|c|c|c|c|c|c|c|}
\hline \multirow{2}{*}{\multicolumn{2}{|c|}{ Macrorregião e cidade }} & \multicolumn{3}{|c|}{2002} & \multicolumn{3}{|c|}{2016} \\
\hline & & \multirow{2}{*}{$\begin{array}{r}\mathbf{I M I}_{\mathbf{i}} \\
0,532\end{array}$} & \multirow{2}{*}{$\begin{array}{r}\begin{array}{r}\mathbf{V A I}_{\mathrm{i}} / \\
\mathrm{VAl}_{\mathrm{j}}(\mathbf{1})\end{array} \\
8,10 \%\end{array}$} & \multirow{2}{*}{$\begin{array}{r}\mathbf{P V A \mathbf { I } _ { \mathbf { i } }} \\
2,50 \%\end{array}$} & \multirow{2}{*}{$\begin{aligned} & \mathbf{I M I}_{\mathbf{i}} \\
& 0,307\end{aligned}$} & \multirow{2}{*}{$\begin{array}{l}\mathbf{V A l}_{\mathbf{i}} / \\
\mathbf{V A l}_{\mathbf{j}} \\
6,80 \%\end{array}$} & \multirow{2}{*}{$\frac{\mathbf{P V A l}_{\mathbf{i}}}{1,80 \%}$} \\
\hline Vale & Blumenau & & & & & & \\
\hline Vale & Brusque & 0,741 & $3,20 \%$ & $1,00 \%$ & 0,697 & $2,90 \%$ & $0,80 \%$ \\
\hline Norte & Jaraguá do Sul & 0,752 & $6,50 \%$ & $2,00 \%$ & 0,717 & $4,90 \%$ & $1,30 \%$ \\
\hline \multirow[t]{2}{*}{ Norte } & Joinville & 0,704 & $17,40 \%$ & $5,40 \%$ & 0,642 & $11,60 \%$ & $3,10 \%$ \\
\hline & Total & & $35,20 \%$ & $10,90 \%$ & & $26,20 \%$ & $7,00 \%$ \\
\hline
\end{tabular}

Fonte: Elaborado pelos autores.

Notas: Dados numéricos arredondados.

(1) Relação entre o Valor Adicionado Industrial da cidade $i$ com o Valor Adicionado Industrial estadual $j$.

\section{Evolução industrial nos municípios catarinenses a partir da Análise Exploratória de Dados Espaciais Univariada}

Nesta seção são feitas análises espaciais do IMI. Para tanto, a pesquisa lançou mão de estatísticas de autocorrelação espacial local e global, em especial a estatística Local de Moran, com o intuito de identificar a formação de grupos.

Em relação ao indicador global de autocorrelação espacial (ou Moran's I) os 
valores obtidos para 2002, 2009 e 2016 foram respectivamente 0,200, 0,218 e 0,256 . Estes valores sugerem a rejeição da hipótese de aleatoriedade espacial como pode. Também indicam melhoria no grau de explicação, sinalizando a emergência de novos clusters industriais.

Percorrendo as macrorregiões do Estado, é no Vale do Itajaí e no Norte Catarinense - que são contíguos - que há o maior número de cidades de clusters alto-alto nos três anos (foram identificados 20 municípios nesse cluster). Segundo a FIESC (2017), o Vale do Itajaí e Norte Catarinense possuem destaque no setor industrial com os segmentos metal-mecânico e metalurgia, têxteis e confecções, automotivo, móveis e madeira, produtos químicos, plásticos e energia. Do total exportado das duas regiões, $44 \%$ é referente a produtos industrializados-(MDIC, 2019).

No Sul, destaque para Cocal do Sul, presente como cluster alto-alto nos 3 anos analisados. Em 2002, a região contava com 6 cidades: Braço do Norte, Cocal do Sul, Criciúma, Morro da Fumaça, Sangão e Treze de Maio. Já em 2016, permaneceram apenas 2 municípios, Cocal do Sul e Içara. O Oeste não apresentou nenhum cluster alto-alto em 2002.

Em 2016, São José do Cedro foi o único cluster alto-alto da região Oeste. Madeira \& Mobiliário foi o subsetor que mais empregou naquele ano, enquanto o setor manufatureiro representou 34\% dos empregos (MTE, 2019). Na pauta de exportações em 2016, encontram-se exclusivamente os produtos industriais oriundos da indústria moveleira (COMEXTSTAT, 2019).

Apesar da Grande Florianópolis ter exibido Canelinha neste grupo em 2002 e 2009, vale salientar que esta cidade é contígua ao Vale de Itajaí. A indústria foi o setor que mais empregou em 2009 na cidade, principalmente a produção de minerais não metálicos, não tendo efetuado exportações.

A seguir, na Tabela 10, apresentam-se as cidades de cluster alto-alto e os respectivos desdobramentos nos empregos, valor adicionado e exportações. Já a Figura 3 em seguida, apresenta os quatro tipos de clusters do Indicador de Associação Espacial (LISA). O total de cidades de clusters alto-alto recuou desde 2002, embora tenha apresentado recuperação entre 2009 e 2016. O impacto que estas cidades produzem nos empregos, valor adicionado e exportações do setor industrial recuou ano após ano, cerca de 20 pontos percentuais em pouco mais de uma década. Mesmo que o número de clusters alto-alto tenha aumentado entre 2009 e 2016, estas cidades já não concentram o setor industrial tanto quanto em 
2002. Verifica-se um movimento de perda da capacidade de concentrar resultados econômicos nestes clusters.

Tabela 10 - Clusters alto-alto em Santa Catarina e a respectiva representatividade nos anos de 2002, 2009 e 2015

\begin{tabular}{|c|c|c|c|c|}
\hline & \multicolumn{4}{|c|}{ Impacto das cidades de cluster alto-alto (\%) } \\
\hline & 2002 & 2009 & 2016 & $\begin{array}{c}\text { Diferença } \\
\text { (p.p.) }\end{array}$ \\
\hline TOTAL DE CIDADES & $13,3 \%$ & $9,9 \%$ & $11,5 \%$ & \\
\hline Emprego Industrial... & $53,1 \%$ & $47,1 \%$ & $34,5 \%$ & $-18,6$ \\
\hline Emprego Total & $18,7 \%$ & $15,6 \%$ & $10,5 \%$ & $-8,2$ \\
\hline Valor Adicionado Industrial.... & $51,8 \%$ & $47,0 \%$ & $30,2 \%$ & $-21,6$ \\
\hline 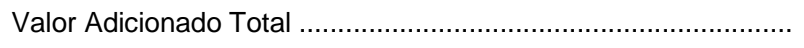 & $16,2 \%$ & $14,5 \%$ & $8,2 \%$ & $-8,0$ \\
\hline Exportações Industriais......... & $65,8 \%$ & $58,3 \%$ & $45,6 \%$ & $-20,2$ \\
\hline Exportações Totais & $40,0 \%$ & $28,1 \%$ & $21,6 \%$ & $-18,4$ \\
\hline
\end{tabular}

Fonte: IBGE, MTE e MDIC.

Nota: Dados transformados pelos autores.

Figura 3 - Indicador Local de Associação Espacial (LISA) do IMI nos municípios catarinenses em 2002, 2009 e 2016
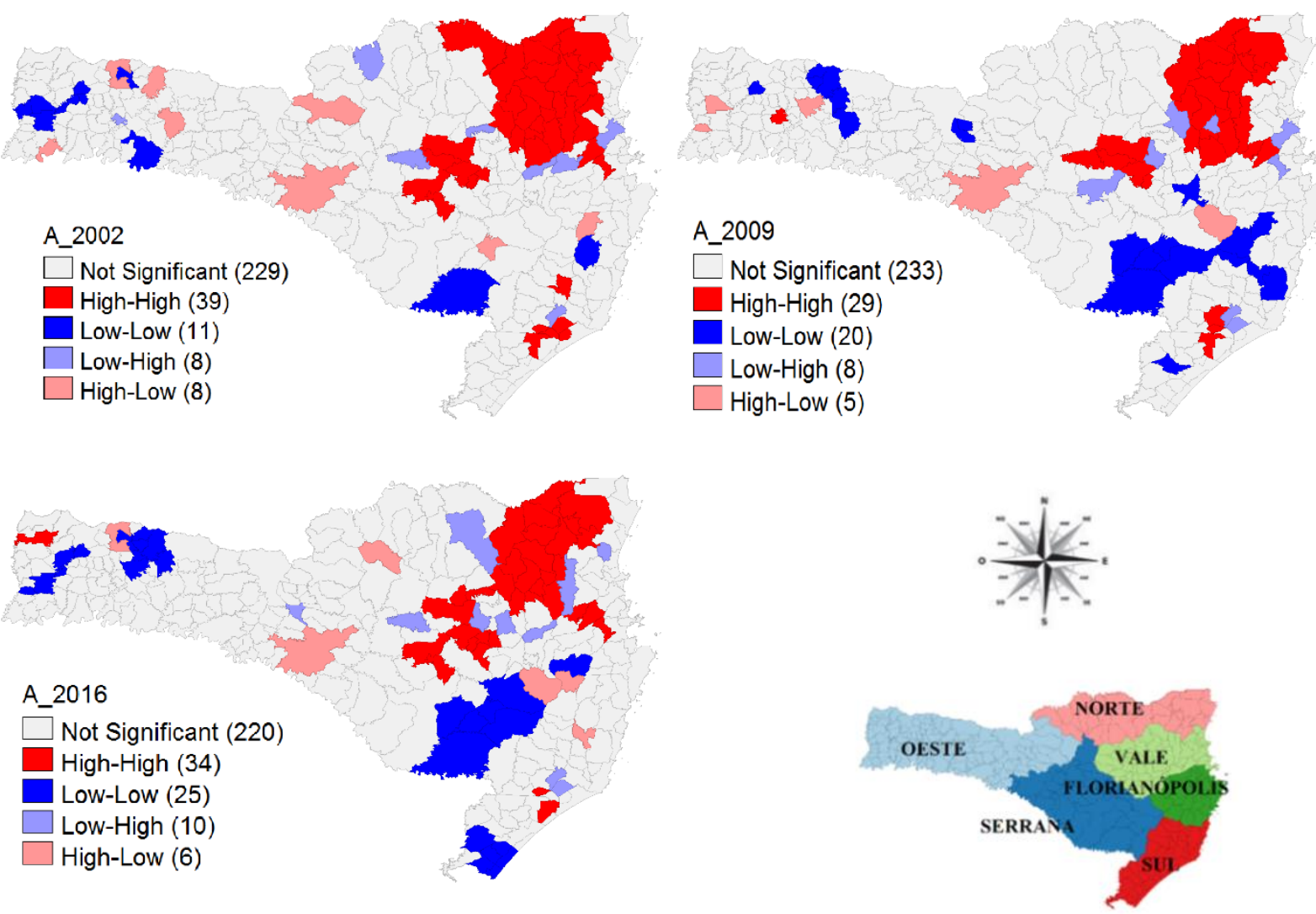

Fonte: Elaborado pelos autores em GeoDa. 
A queda do número de cidades de cluster alto-alto é de cinco municípios durante os anos avaliados. Eram $39 \mathrm{em} 2002$ de acordo com a Figura 3, passando a 29 em 2009 e totaliza 34 cidades em 2016. No ano de 2016, a indústria das cidades de cluster alto-alto era composta principalmente pelo setor têxtil, seguido pelo mecânico, metalúrgico e moveleiro. As exportações estão concentradas nos itens industrializados-(MDIC, 2019).

No sentido oposto, conforme a Figura 3, municípios cujos clusters eram abaixo da média, com vizinhos na mesma situação, aumentaram de 11 cidades em 2002, para $20 \mathrm{em}$ 2009, alcançando $25 \mathrm{em}$ 2016. A região Oeste do Estado concentra o maior número dos clusters baixo-baixo. Eram 9 em 2008, aumentando para 12 em 2016. A única cidade da região presente em todo período foi Santa Terezinha do Progresso.

Os mapas de associações espaciais demonstrados na Figura 3 também indicam outliers. São dois tipos, um representado por clusters baixo-alto e o outro por alto-baixo. É no Vale do Itajaí que há a maioria das cidades do primeiro tipo. Destaca-se a cidade de Blumenau neste segmento em 2016, que em 2002 e 2009 tinha na indústria grande realce setorial e compunha o cluster alto-alto. Em 2016, Blumenau passa a compor o cluster baixo-alto, ainda que seu VAl esteja entre os 59 maiores do Estado. Por último, em relação às associações alto-baixo, eram $8 \mathrm{em}$ 2002 e se reduzem a 6 em 2016 de acordo com a Figura 3. A região Oeste era que apresentava a maior quantidade de cidades em 2002, com Caçador, Mondaí, São Domingos, Xanxerê e São Miguel do Oeste. Esta última, inclusive, é a única que permaneceu da região em 2016.

Logo, pode-se concluir que houve declínio no período 2002 e 2009 e recuperação no período 2009 a 2016 e embora haja indícios de desindustrialização, como o forte impacto da crise ainda não se dissipou da economia catarinense, não se pode afirmar que um processo de desindustrialização esteja em andamento.

\section{Considerações Finais}

O presente estudo discutiu a evolução e as transformações da indústria catarinense e a análise exploratória de dados espaciais permitiu chegar a duas principais conclusões. 
A primeira é que é possível rejeitar a hipótese de aleatoriedade na distribuição da indústria em Santa Catarina nos anos de 2002, 2009 e 2016. A atividade possui autocorrelação espacial o que equivale a dizer que cidades cujos setores industriais são relevantes para sua economia são vizinhas de cidades com aspecto semelhante. Verificou-se que nesses anos, principalmente nas regiões do Vale do Itajaí e Norte Catarinense há a maior concentração desta relação. Uma aglomeração menor, porém consistente, também se dá no Sul do estado. As atividades industriais que se concentram nestas regiões são as de metal-mecânico e metalurgia, têxteis e confecções, automotivo, móveis e madeira, produtos químicos, plásticos e energia.

A segunda é que o número de clusters alto-alto vêm diminuindo. Em 2002 havia 39 cidades que compunham os clusters alto-alto. No próximo ano de avaliação em 2009, o número se reduz para 29 e em 2016 retoma crescimento e chega a 34 , embora a contribuição destas cidades nos empregos, valor adicionado e exportações não tenha majorado sua representatividade, nem no total do Estado e nem no segmento industrial. $O$ Vale do Itajaí e Norte Catarinense, que são contíguos, são as regiões que mais centralizam os setores industriais. Ao mesmo tempo, são as áreas que houve redução no número de cidades. Foram 7 cidades que ao longo deste período analisado deixaram de compor as cidades que se destacam no setor industrial cujos vizinhos também são destaque. Em sentido inverso às áreas que se sobressaem nas estruturas municipais voltadas à indústria, surgiram no período analisado cidades cuja importância do setor manufatureiro e de seus vizinhos estão abaixo da média do Estado. Em 2002 eram 11 cidades de cluster baixo-baixo e em 2016 foram registradas 25. Tanto as crises de 2007 e 2015 são fatores que não permitem afirmar se há um processo de desindustrialização em curso.

Em relação a trabalhos futuros e aprofundamento no tema, é possível o uso de modelos de econometria espacial, análise das políticas utilizadas pelo Estado de Santa Catarina que estimulam o desenvolvimento local e regional, análise do desenvolvimento industrial local com concentração de renda, emprego, saúde e educação.

\section{Referências Bibliográficas}

ANSELIN, L. Exploring Spatial Data with GeoDa: A Workbook. Illinois: Center For Spatially Integrated Social Science, 2005. 226 p. Disponível em: <http://www.csiss.org/clearinghouse/ GeoDa/geodaworkbook.pdf>. Acesso em: 05 set. 2018. 
ANSELIN, L. GeoDa Documentation. 2018. Disponível em: <http://geodacenter.github.io/ documentation.html>. Acesso em: 05 set. 2018.

BARBOSA FILHO, F. H.; PESSÔA, S. A. Pessoal ocupado e jornada de trabalho: uma releitura da evolução da produtividade no Brasil. Revista Brasileira de Economia, [s.I.], v. 68, n. 2, p.149-169, jun. 2014. FapUNIFESP (SciELO). http://dx.doi.org/10.1590/s003471402014000200001.

BRESSER-PEREIRA, L. C. Doença Holandesa e sua neutralização: Uma abordagem ricardiana. Dez. 2007. Disponível em: <http://www.bresserpereira.org.br/view.asp? cod $=2470>$. Acesso em: 01 out. 2018.

CARVALHO, M. A.; SILVA, C. R. L. Mudanças na pauta das exportações agrícolas brasileiras. Revista de Economia e Sociologia Rural, [s.I.], v. 46, n. 1, p.53-73, mar. 2008. FapUNIFESP (SciELO). http://dx.doi.org/10.1590/s0103-2003200 8000100003.

CONCEIÇÃO, O. A. C.. A dimensão institucional do processo de crescimento econômico: inovações e mudanças institucionais, rotinas e tecnologia social. Economia e Sociedade, Campinas, v. 17, n. 132, p.85-105, abr. 2008.

CROCCO, M. A.; GALINARI, R.; SANTOS, F.; LEMOS, M. B.; SIMÕES, R. Metodologia de identificação de aglomerações produtivas locais. Nova Economia, [s.l.], v. 16, n. 2, p.211241, ago. 2006. FapUNIFESP (SciELO). http://dx.doi.org/10.1590/s0103-

63512006000200001 .

CRUZ, B. O.; SANTOS, I. R. S. Dinâmica do emprego industrial no Brasil entre 1990 e 2009: uma visão regional da desindustrialização. Texto para Discussão, Rio de Janeiro, v. -, n. 1673, p.1-49, nov. 2011. Disponível em: <http://www.ipea.gov.br>. Acesso em: 15 abr. 2019.

CURADO, M. Industrialização e desenvolvimento: uma análise do pensamento econômico brasileiro. Econ. soc., Dez 2013, vol.22, no.3, p.609-640. ISSN 0104-0618

FIESC (Ed.). Santa Catarina em Dados. Florianópolis: Federação das Indústrias do Estado de Santa Catarina, 2015. 192 p. Publicação Anual. Disponível em: <http://fiesc.com.br /sites/default/files/inlinefiles/sc_em_dados_site_2015.pdf>. Acesso em: 01 out. 2018.

FIESC (Ed.). Santa Catarina em Dados. Florianópolis: Federação das Indústrias do Estado de Santa Catarina, 2017. 240 p. Disponível em: <http://fiesc.com.br/economia/santacatarina-dados>. Acesso em: 01 out. 2018.

FURTADO, C. Desenvolvimento e subdesenvolvimento. Rio de Janeiro: Fundo de Cultura, 1961.

FURTADO, C. Formação econômica do Brasil. 8. ed. São Paulo: Companhia Editora Nacional, 1968.

HIRATUKA, C.; SARTI, F. Transformações na estrutura produtiva global, desindustrialização e desenvolvimento industrial no Brasil: uma contribuição ao debate. Texto Para Discussão, Campinas, v. -, n. 255, p.1-22, jun. 2015.

IBGE (Brasil). Produto Interno Bruto dos Municípios. 2019. Disponível em: <https://sidra.ibge.gov.br/pesquisa/pib-munic/tabelas>. Acesso em: 01 fev. 2019. (a)

IBGE (Brasil). Tabela 3653: Produção Física Industrial, por seções e atividades industriais. Disponível em: < https://sidra.ibge.gov.br/tabela/3653>. Acesso em: 28 abr. 2019. (b) 
IBGE (Brasil). Tabela 5642: Índice de Gini da Distribuição do rendimento mensal das pessoas com 15 anos ou mais de idade, com rendimento. Disponível em: <https://sidra.ibge.gov.br/tabela/5642\#notas-tabela>. Acesso em: 28 abr. 2019. (c)

KALDOR, N. A Model of Economic Growth. The Economic Journal, v. 67, n. 268, p. 591624. Dez. 1957. Disponível em: < http://www.jstor.org/stable/2227704>. Acesso em: 14 set. 2018.

LANGONI, C. G. A economia da transformação. Rio de Janeiro: Biblioteca do Exército, 1976. 213 p. 135 v. (Coleção General Benício).

MARSHALL, A. Principles of economics. Vol. 1. Macmillan And Co., Limited; Londres, 1898.

MDIC (Brasil). ComexStat: Exportação e Importação Municípios. 2019. Disponível em: <http://comexstat.mdic.gov.br/pt/municipio>. Acesso em: 01 fev. 2019.

MTE (Brasil). Bases Estatísticas RAIS e CAGED. 2019. Disponível em: <http://bi.mte.gov.br/bgcaged/inicial.php>. Acesso em: 01 fev. 2019.

MORCEIRO, P. C.; GUILHOTO, J. J. M. Desindustrialização setorial e estagnação de longo prazo da manufatura brasileira. Working Paper Series, São Paulo, p.1-28, jan. 2019.

Disponível em: <http://www.repec.eae.fea.usp.br/documentos/Morceiro_ Guilhoto_01WP.pdf>. Acesso em: 15 abr. 2019.

OECD (Ed.). Handbook on Constructing Composite Indicators: Methodology and User Guide. Paris: OECD Publications, 2008. 158 p. Disponível em: <https://www.oecd.org/sdd/42495745.pdf>. Acesso em: 03 set. 2018.

OREIRO, J. L.; FEIJÓ, C. A. Desindustrialização: conceituação, causas, efeitos e o caso brasileiro. Revista de Economia Política, [s.I.], v. 30, n. 2, p.219-232, jun. 2010.

FapUNIFESP (SciELO). http://dx.doi.org/10.1590/s0101-31572010000200003.

PEROBELLI, F. S. ; BASTOS, S. Q. A.; OLIVEIRA, J. C. Avaliação sistêmica do setor industrial brasileiro: 1995-2009. Estudos Econômicos (São Paulo), [s.l.], v. 47, n. 1, p.125152, mar. 2017. FapUNIFESP (SciELO). http://dx.doi.org/10.1590/ 0101-416147151fsj.

PREBISCH, Raúl. O Desenvolvimento Econômico da América Latina e seus Principais Problemas . Revista Brasileira de Economia, Rio de Janeiro, v. 3, n. 3, p. 47-111, jul. 1949. ISSN 1806-9134. Disponível em: <http://bibliotecadigital.fgv.br/ojs/index.php/rbe/ article/view/2443/1767>. Acesso em: 07 Set. 2018.

ROWTHORN, R.; RAMASWAMY, R. Growth, Trade, and Deindustrialization. Imf Staff Papers: A journal of IMF, Washington, v. 46, n. 1, p.17-41, mar. 2009. Disponível em: <https://www.imf.org/external/Pubs/FT/ staffp/1999/03-99/pdf/rowthorn.pdf>. Acesso em: 01 out. 2018

SCHUMPETER, J. A. Capitalismo, socialismo e democracia. Rio de Janeiro: Zahar Editores, 1984, p. 110-116.

SOLOW, R. M. A Contribution to the Theory of Economic Growth. The Quarterly Journal Of Economics, [s.I.], v. 70, n. 1, p.65-94, fev. 1956. Oxford University Press (OUP). http://dx.doi.org/10.2307/1884513.

TREGENNA, F. Characterising deindustrialisation: an analysis of changes in manufacturing employment and output internationally. Cambridge Journal of Economics, Oxford University Press, vol. 33(3), p. 433-66, mai. 2009. 


\section{NOTAS DE AUTOR}

\section{CONTRIBUIÇÃO DE AUTORIA}

Thiago Pegoretti Moser - Concepção. Coleta de dados. Análise de dados. Participação ativa da discussão dos resultados. Elaboração do manuscrito. Revisão.

Marcia Gabardo da Camara - Concepção. Participação ativa da discussão dos resultados. Revisão. Aprovação da versão final do trabalho.

Carlos Eduardo Caldarelli - Concepção. Revisão. Aprovação da versão final do trabalho.

\section{FINANCIAMENTO}

Não se aplica.

\section{CONSENTIMENTO DE USO DE IMAGEM}

Não se aplica.

\section{APROVAÇÃO DE COMITÊ DE ÉTICA EM PESQUISA}

Não se aplica.

\section{CONFLITO DE INTERESSES}

Não se aplica.

\section{LICENÇA DE USO}

Este artigo está licenciado sob a Licença Creative Commons CC-BY. Com essa licença você pode compartilhar, adaptar, criar para qualquer fim, desde que atribua a autoria da obra.

\section{HISTÓRICO}

Recebido em: 11-09-2019

Aprovado em: 22-09-2020 